\title{
Study of animal welfare status in dairy cow herds in Hungary - looking for causes of lameness
}

\author{
Richard Gudaj ${ }^{1}$ - István Komlósi ${ }^{1}$ - Endre Brydl ${ }^{2}$ \\ ${ }^{1}$ Centre for Agricultural and Applied Economics Science \\ Faculty of Agricultural and Food Sciences and Environmental Management \\ University of Debrecen \\ ${ }^{2}$ Department of Animal Hygiene \\ Faculty of Veterinary Science \\ Szent István University in Budapest. \\ rgudaj@agr.unideb.hu
}

Keywords: Lameness, dairy welfare, multivariable modeling, herd health, risk factor

SUMMARY

In the last 20-30 years, lameness in cattle was found to be third the most influential disease next to mastitis and reproduction disorders. Studies have been established to explore reasons for lameness and prevention. The problem with more robust prevention plans is that knowledge and research evidence is not strong enough to run an effective prevention plan. The aim of the research is to look for reasons of lameness by observing number of cows on 6 farms during 2 lactations. Performance data will be put together to body condition score (BCS) and lameness scores. Other examination is focused on monitoring of 40 farms. This part of the project is more related to extension, collecting and sharing solutions for decreasing lameness. Producers are advised what kind of measures are possible to reduce occurrence of lameness. Effectiveness of those actions will be measured at the end of the study. The first preliminary results show lack in almost all preventive measures needed to be taken in minimizing lameness. Those areas are related to poor facilities, lack of straw, problems with labor and basic management.

\section{INTRODUCITON}

Lameness has been recognized as a multifactorial condition (Espejo and Endres, 2007), severely-decreased animal welfare (Webster, 2001) and is an important constraint to the dairy industry (Kossaibati and Esslemont, 1997). This is an economically important production disease (Kaneene and Hurd, 1990) and losses include reduced milk yield and quality, weight loss and death (Webster, 2001). Disease has an impact on decreasing reproductive performance (Sprecher et al., 1997) and increasing treatment costs (Weaver, 1984). The cost of premature culling is also highlighted (Enting et al., 1997). Cows with low milk yield and lameness and claw lesions are more likely to be culled (Sogstad et al., 2007). Lameness is the reason for culling $16 \%$ of dairy cows sent to slaughter in the US (NAHMS, 2002) and has an impact on decreased carcass value of culled cows (Van Arendonk et al., 1984). However some authors disagree with the common opinion about the disease and its impact on culling (Barkema et al., 1994; Milian-Suazo et al., 1988). The disease has an association with pain (Whay et al., 2003) and distress in dairy cattle (Webster, 1986). Hoof health and locomotion are also compromised when dairy cows spend less time lying down (Hassall et al., 1993).

Proper nutrition management can lower the number of hoof problems in dairy herds (Galindo and Broom, 2000). Laminitis often is a result of a wide range of factors which include metabolic and digestive disorders; stress associated with parturition; mastitis; mertritis; hard or poorly bedded stalls; too little exercise; excessive body weight; and poor nutritional management. The first goal of this project is to look for causes of lameness during two years observations. The second objective of the research is to discover new areas on the farms and management procedures either developing or decreasing lameness. Lastly, the study aims to provide farmers with extension knowledge from literature and records collected from 40 farms observed during examination.

\section{MATERIALS AND METHODS}

For the first part of the project, 6 farms were chosen for observation. Every month, 5 cows from first lactation and 5 cows from second lactation are taken for monitoring. Every month, an extra ten cows are found. Cows will be added over the period of one year. During the next year, the same cows will be observed. In total, there will be 720 cows minus culled cows and months when there will be less than 5 cows from each lactation. Cows are checked regarding their locomotion score and body condition score. The data will be confronted with milk yield, fat, protein, SCC and carbamide and others from each month cows were checked.

For the second part of the research study, 18 dairy farms in Hungary were recruited into the study which is in progress (target - minimum 40). The selection was firstly created on a principle of searching for as different farms as possible. Among farms chosen are farms which are different in: ownership (private and cooperative), size (from 56 to 850 milking cows), husbandry systems (free stall, straw yard), access to the pasture (yes, no), 
scraping system (automatic, tractor), age (modern, old ones), number of animals per water troughs (12-120), surface quality ( 1 - relatively dry, no holes and not slippery; 2 - wet or some holes or slippery; 3 - wet, some holes and slippery). Farms differ also in more aspects which are not mentioned in this short material. Lameness scoring system based on already existing method of assessing locomotion score (Table 1) developed by Sprecher et al. (1997). This scoring system was chosen because it matched the overall scoring system used in the protocol, was robust and provided the level of information required for analysis. Every farm is assessed regarding to measures taken for lameness prevention (Table 2). Each measure has a specific role in development of the disease. After a farm visit, each manager obtains a protocol related to neglected areas on the farms and possible improvements. At the end of the study, farms will be checked again for assessing if suggestions given were applied. Then, lameness status will be checked again for measuring effectiveness of improvements.

Interpretation of Locomotion Scoring of Dairy Cattle (Sprecher et al.1997) used in the study

Stands and walks with an arched back and short strides with one or more legs. Slight sinking of dew-claw in limb opposite to the affected limb may be evident.

Arched back standing and walking. Favoring one or more limbs, but can still bear some weight on them. Sinking of the dew-claws is evident in the limb opposite to the affected limb.

Severely lame

Pronounced arching of back. Reluctant to move, with almost complete weight transfer off the affected limb.

Footbath

\section{Solution used}

Trimming

Who's trimming?

Records

Floor type

Feed yard surface

Parlor surface

Scraping method

Passageway dimensions

\section{Bedding - cleanliness}

Bedding - softness

Extra free-stalls

Lunge Area

Free-stall Length

Free-stall Width

Neck rail-curb horizontal

Neck rail-bottom

Brisket board

Animals/water troughs Access

Feed space per head

Width of feed yard

Grooming brushes

\section{Measures observed on the farms}

Table 2

Needed for assessing number and quality of applications. Footbath solutions usually contain copper sulphate, formaldehyde or blend of organic acids and tea tree oil. Those are antibiotics or caustic chemicals. If used in high concentration can have a caustic effect on the skin.

Minimum 2 trimmings are advised per year.

All cows are advised to be trimmed by professional trimmer, rather than by stockman and a professional trimmer or only by stockman.

There should be records of lame cows, so the treatment can be done quickly and directly to the cow which needs it first.

Groove flooring was found to be friendlier for cows' hooves than non-grooved concrete and slatted surface was found to be the least safe. Rubber mats are making the least damage do the hooves.

Passageways scraped by tractor were linked with fewer lame cows. Automatic scrapers are pushing a high wave of slurry which highly contaminates hooves and legs.

Passageways $350 \mathrm{~cm}$ and wider are better for cows, because the manure, slurry and dung is spread on bigger area.

Amount of straw has an impact on laying comfort in cubicles. Lameness is also affected by providing enough time for hooves relief and not standing in the muck outside of the box. Prolonged standing has been associated with the presence of sole ulcers (Cook et al., 2004) and increased foot lesions and lameness (Singh and Ward, 1993). Housing on concrete has a more deleterious effect on claw health than housing on soft surfaces such as straw. Bedding keeps the feet dry which has a positive effect on claw health and may play an important role in the prevention of claw lesions (Leonard et al., 1994).

In free-stall barns, cows are less likely to lie in dirty alleyways if free stalls are of adequate size, and at least nine stalls per 10 cows are provided.

Measures needed for accessing how comfortable the cubicle is. That is extremely important in avoiding perching behavior (standing half in cubicle and half in alley). What is more cows are suppose to find boxes friendlier to lay in than standing what causes lameness.

Competitions for limited resources makes cows are pushing each other making possible damages to hooves.

Cows looking for any different areas for grooming than brushes are more likely to slip or to stand in not proper way. 


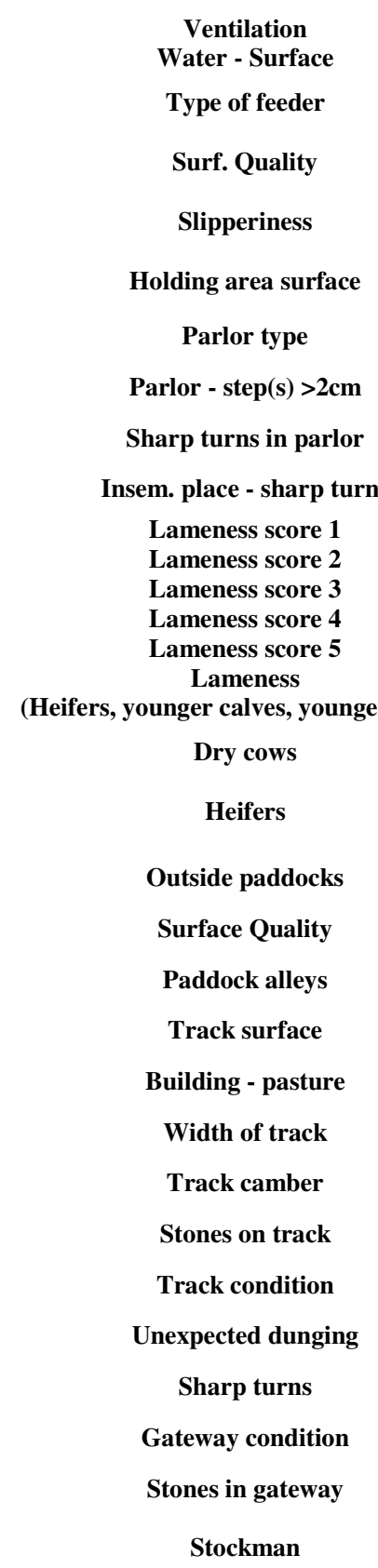

\author{
Moisture is creating faster hoof damage and easier way for bacteria development. \\ Feeders 10-15 cm higher than the surface cows are standing are easier to access \\ for cows. \\ Clean flooring with good grip makes fewer occasions for slipping and hooves \\ contamination. \\ Slippery floors make higher occurrence of locomotion problems. Damage to the \\ wall of the hooves (sole ulcers and digital dermatitis). \\ Cows in holding area are interacting with each other and putting a huge amount of \\ weight on hooves in the way they might be easily damaged. \\ Fewer sharp turns makes fewer opportunities for hooves damages.
}

All obstacles are possible areas for hooves damages by sharp turning or avoiding unpleasant places.

Lameness scoring for differentiating differences in occurrence of disease. Higher scores are related to bacteria, very bad flooring and very hard neglected cases. Lower scores are related rather to physical aspects (slipperiness, highs slopes, steps).

On some farms lameness development is found even among young animals where poor conditions are provided (holes, stones, and a lot of muck).

Dry cows kept in stalls with access to straw yards during dry period have more chance to recover by lying in softer and more comfortable positions.

Heifers given adaptation time are easier taking positions in cubicles. There is less time they are standing and affecting their hooves.
All conditions related to access to paddocks and the alleys' conditions. Ideally, cows should be provided with access to pasture (paddock) with good quality alleys and surface. Preferably there should be soft, dry surface as close to the buildings as possible. Track should be wide enough, has the camber, with no stones, no mud, no muck, no sharp turns. The gateway should be wide and dry.

Rushed cows are in danger of stepping in uncontrolled way by shorting their strides. Cows are not able to focus where they are stepping and damages to hooves and legs might occur.

\section{RESULTS AND DISCUSSION}

Initial observations of results from the first part of the research study provide evidence that lameness increases greatly 3-5 months after calving, which is in agreement with Cook et al. (2004). There is need to wait for more data to be collected to be able to see clearer results.

Preliminary results of second part of the study show very clearly basic relations between lameness and procedures taken on particular farms. Generally there is lack in almost all preventive measures needed to be taken in minimizing lameness. On many farms, foot bathing is performed very rarely for long periods of time, e.g. twice a year for two weeks. This method might affect skin burning and then hooves are contaminated for a long time until another bathing is performed. Trimming in average is performed more rarely than recommended (twice a year), with some farms not trimming cows for 1.5-2 years. Half of the farms employ a trimming service. $33.3 \%$ of the farms are performing trimming on their own. Similar to Sogstad et al. (2007), those farms are found with higher prevalence of lameness. $16.6 \%$ of farms are cooperating with professional trimmers and sharing the job with them. Only $44.4 \%$ of farms are keeping records of lame cows. Such farms are more effective in keeping cows' hooves in better condition. Passageways wider than $3.5 \mathrm{~m}$ are provided on $50 \%$ of the farms. This is crucial in spreading muck and dung on bigger area, so hooves are less contaminated. Hooves' health is also compromised on those of the farms which are providing less the $10 \%$ of extra stalls. In those cases animals are forced to stand for longer period and hard flooring is making pain. On average, there are $8.2 \%$ of 
extra cubicles in all farms. Limited number of water troughs ( 1 water trough per 39.2 animals) is creating a highly competitive situation, when cows might fight for access to resources and slip or hurt themselves. On a scale from 1 (not slippery, dry) to 3 (highly slippery, highly contaminated with muck), all the farms are placed with the result 2.4. On farms with many dirty areas with muck and dung, risk of lame and severely lame cows is increased. Of those farms providing paddocks and pastures, $65 \%$ of tracks are highly dangerous for cows with stones, mud, sharp corners, unexpected dunging and impropriate width of the track.

\section{CONCLUSIONS}

There is an immediate need for showing to farmers the weakest areas on the farms. The points highlighted in the preliminary results confirm flooring quality and basic management procedures to be neglected. For those reasons, cows are more likely to walk in manure which provides an acidic environment with bacteria. In many cases, if cubicles (brisket board, lounge area, neck rail) are not set up properly, cows are forced to stand than to lay. Comfort is very important in cows' daily routine, because animals need time for relaxing, but that is highly limited. Hungarian dairy enterprises (particularly those in project) lack in good quality, modern barns. Most of them are refurbished old buildings which, in many cases, even some changes were applied, still can not meet cows' expectations. There is an increasing interest of farm managers and farmers about lameness. Farmers are aware of the problem and like in other studies (Espejo and Endres, 2007; Whay et al., 2003) underestimate the lameness occurrence.

In some cases, almost $50 \%$ of cows with locomotion scores 2 (mildly lame) and 3 (moderately lame) are not found to be problematic by farm managers. Most of them are only interested in scores 4 (lame) and 5 (severely lame). That shows how stockmen are sensitive to animal pain and what kind of perception they have. Such attitudes arise from the manner of observing cows everyday and the perception of these people seems to have narrower definitions of which cow is lame and which is not. From the authors' experience, those farms with high percentages of cows with locomotion scores 2 and 3 are related to physical aspects of flooring and facilities rather than bacteria and damaged tissue. If those farmers were able to keep such a low number of lame and severely lame cows, this means that they provided a lot of clean and dung-free areas for cows. From that point of view, there is just a short step to providing non-slippery and non-harsh flooring. This research aims to suggest to farmers all possible measures on their farms to provide as fewer as possible harmful conditions for cows' hooves and legs.

In all cases, lameness was checked before suggestions were given and other independent improvements were made. The next step will be to check the cows after a period of time, to see whether changes helped to decrease lameness levels or not. This action is in a huge interest of farmers who want to know how much they can gain investing in lameness measures. Another positive aspect is that farmers are highly motivated in discussing how other farmers are dealing with lameness. They also like to compare their farms with results of the rest of the farms involved in the project.

\section{REFERENCES}

Barkema, H. W.-Westrik, J. D.- van Keulen, K. A. S.-Schukken, Y. H.-Brand, A. (1994): The effects of lameness on reproductive performance, milk production and culling in Dutch Dairy Farms, Preventive Veterinary Medicine, 20, $249-259$.

Cook, N.B.-Nordlund, K.V.- Oetzel, G.R. (2004): Environmental Influences on Claw Horn Lesions Associated with Laminitis and Subacute Ruminal Acidosis in Dairy Cows, Journal of Dairy Science, 87, 36-46.

Enting, H.-Kooij, D.-Dijkhuizen, A. A.-Huirne, R. B. M.- Noordhuizen-Stassen, E. N. (1997): Economic losses due to clinical lameness in dairy cattle, Livestock Production Science, 49, 259-267.

Espejo, L. A.-Endres, M. I. (2007): Herd-Level Risk Factors for Lameness in High-Producing Holstein Cows Housed in Freestall Barns, Journal of Dairy Science, 90, 306-314.

Galindo, F.- Broom D. M. (2000): The relationships between social behaviour of dairy cows and the occurrence of lameness in three herds, Research in Veterinary Science, 69, 75-79.

Hassall, S. A.-Ward, W. R.- Murray, R. D. (1993): Effects of lameness on the behaviour of cows during the summer, The Veterinary Record, $132,578-580$

Kaneene, J. B.- Hurd, H. S. (1990): The National Animal Health Monitoring System in Michigan. I. Design, data and frequencies of selected dairy cattle diseases, Preventive Veterinary Medicine, 8, 103-114.

Kossaibat, M. A.- Esslemont, R. J. (1997): The costs of production diseases in dairy herds in England, Veterinary Journal, $154,41-51$.

Leonard, F. C.-Stienezen, I.- O'Farrell, K. J. (1994): Overcrowding at the feeding area and effects on behavior and claw health in Friesian heifers. Pages 40-41 in Proc.10th Int. Symp. Lameness in Ruminants, Lucerne, Switzerland.

Milian-Suazo, F.-Erb, H. N.- Smith, R. D. (1988): Descriptive epidemiology of culling in dairy cows from 34 herds in New York State Preventive Veterinary Medicine, 6, 243-251.

National Animal Health Monitoring System. (2002): Reference of Dairy Health and Management in the United States. US Department of Agriculture: Animal Plant Health Inspection Service. Fort Collins: Veterinary Services CO.

Singh, S.S.- Ward, W.R. (1993): Behaviour of Lame and Normal Dairy-Cows in Cubicles and in a Straw Yard, The Veterinary Record, 133, 204-208. 
Sogstad, Å. M.-Østerås, O.-Fjeldaas-O. Nafstad, T. (2007): Bovine claw and limb disorders related to culling and carcass characteristics, Livestock Science, 106, 87-95.

Sprecher, D. J.-Hostetler, D. E.-Kaneene, J. B. (1997): A lameness scoring system that uses posture and gait to predict dairy cattle reproductive performance, Theriogenology, 47, 1179-1187.

Van Arendonk, J. A. M.-Stokvisch, P. E.-Korver, S. (1984): Factors determining the carcass value of culled dairy cows, Livestock Production Science, 11, 391-400.

Weaver, A. D. (1984): Economic importance of digital diseases in cattle, Bovine Practice, 19, 223-225.

Webster, J. (1986): 'Health and welfare of animals in modern husbandry systems: Dairy cattle', In Practice, 8, 85-89.

Webster, A.J.F. (2001): Effects of housing and two forage diets on the development of claw horn lesions in dairy cows at first calving and in first lactation, The Veterinary Journal, 162, 56-65.

Whay, H.R.-Main, D.C.J.-Green, L.E.- Webster, A.J.F. (2003): Assessment of the welfare of dairy cattle using animal-based measurements: direct observations and investigation of farm records, Veterinary Record 153, 197-202. 